\title{
BMJ Open Effectiveness of meatal cleaning in the prevention of catheter-associated urinary tract infections and bacteriuria: an updated systematic review and meta- analysis
}

Brett Mitchell (D) , ${ }^{1}$ Cassie Curryer, ${ }^{1}$ Elizabeth Holliday (D) , ${ }^{2}$ Claire M Rickard (D) , ${ }^{3,4,5}$ Oyebola Fasugba ${ }^{6}$

To cite: Mitchell B, Curryer C, Holliday E, et al. Effectiveness of meatal cleaning in the prevention of catheterassociated urinary tract infections and bacteriuria: an updated systematic review and meta-analysis. BMJ Open 2021;11:e046817. doi:10.1136/ bmjopen-2020-046817

- Prepublication history and supplemental material for this paper is available online. To view these files, please visit the journal online (http://dx.doi. org/10.1136/bmjopen-2020046817).

Received 10 November 2020 Accepted 19 May 2021

D) Check for updates

(c) Author(s) (or their employer(s)) 2021. Re-use permitted under CC BY-NC. No commercial re-use. See rights and permissions. Published by BMJ.

For numbered affiliations see end of article.

\section{Correspondence to} Professor Brett Mitchell; brett.mitchell@newcastle. edu.au

\section{ABSTRACT}

Objective A systematic review on meatal cleaning prior to urinary catheterisation and post catheterisation and reduces the risk catheter-associated urinary tract infections (CAUTIs) and bacteriuria was published in 2017 , with further studies undertaken since this time. The objective of this paper is to present an updated systematic review on the effectiveness of antiseptic cleaning of the meatal area for the prevention of CAUTIs and bacteriuria in patients who receive a urinary catheter.

Design Systematic review.

Data sources Electronic databases Cochrane Library, PubMed, Embase, The Cumulative Index to Nursing and Allied Health Literature (CINAHL), Medline and Academic Search Complete were searched from 1 January 2016 and 29 February 2020.

Eligibility criteria Randomised controlled trials (RCTs) and quasi-experimental studies evaluating the use of antiseptic, antibacterial or non-medicated agents for cleaning the meatal, periurethral or perineal areas before indwelling catheter insertion or intermittent catheterisation or during routine meatal care.

Data extraction and synthesis Data were extracted using the Cochrane Collaboration's data collection form for RCTs and non-RCTs. Data were extracted by one researcher and then checked for accuracy by a second researcher. Results A total of 18 studies were included. Some potential benefit of using antiseptics, compared with non-antiseptics for meatal cleaning to prevent bacteriuria and or CAUTI was identified ( $0 \mathrm{R} 0.84,95 \% \mathrm{Cl} 0.69$ to $1.02 ; \mathrm{p}=0.071$ ). Antiseptics (chlorhexidine or povidine-iodine) may be of value for meatal cleaning on the incidence of CAUTI, compared with comparator agents (saline, soap or antimicrobial cloths) (OR=0.65, 95\% Cl 0.42 to $0.99 ; p=0.047$ ).

Conclusion There is emerging evidence of the role of some specific antiseptics (chlorhexidine) prior to urinary catheterisation, in reducing CAUTIs, and some potential benefit to the role of antiseptics more generally in reducing bacteriuria. PROSPERO registration number CRD42015023741.

\section{INTRODUCTION}

Indwelling or intermittent urinary catheter use can result in bacteriuria which may signify
Strengths and limitations of this study

- A summary of the latest evidence on the role of antiseptics in reducing catheter-associated urinary tract infections.

- Subgroup analysis to explore effects using different antiseptics.

Heterogeneity of population groups is a limitation.

either colonisation (catheter-associated asymptomatic bacteriuria) or symptomatic infection (catheter-associated urinary tract infections (CAUTIs)). ${ }^{1}$ CAUTIs are a common but preventable nosocomial infection. They account for around 70\%-80\% of hospital-acquired urinary tract infections (UTIs), are associated with longer length of hospital stay and increased risk of morbidity and mortality. ${ }^{2-5}$ In the UK, economic analyses of hospital inpatient costs estimated that CAUTIs caused over 45000 excess bed days, 1467 deaths, and a loss of 10471 qualityadjusted life years (QALYs). ${ }^{6}$ The burden of CAUTIs for both patients and health services highlight the importance of reducing these infections in healthcare settings.

Various strategies for reducing the risk of CAUTIs have been proposed. These include reducing unnecessary catheter use, practising appropriate catheter insertion and maintenance, and prompt removal of urinary catheters. $^{7-9}$ A systematic review published in 2017 explored the effect of using different meatal (peri-urethral) cleaning agents prior to urinary catheter insertion on the incidence of UTIs. ${ }^{10}$ Meatal cleaning was identified by the review as one element of urinary catheter care which may reduce CAUTI risk. ${ }^{10}$ However, the review also identified uncertainty in the 
available evidence for the effectiveness of this practice. Since this publication, there have been further studies published on this topic, ${ }^{11} 12$ and the evidence base is still evolving. Moreover, some previous studies were limited by bias (eg, selection bias, non-masking of intervention). ${ }^{11} 13$ Given the potential importance of meatal cleaning for preventing UTIs and informing clinical practice and guidelines, we believed it was important to update the evidence base. ${ }^{10}$ In this paper, we present findings from an updated systematic review and meta-analysis. The aim of this review is to determine the effectiveness of antiseptic cleaning of the meatal area, for preventing CAUTI and bacteriuria.

\section{METHODS}

A protocol was developed to guide the conduct of the systematic review and meta-analysis, and we have used a reporting approach consistent with the Preferred Reporting Items for Systematic Reviews and Meta-analyses (PRISMA) statement. ${ }^{14}$ The methodological approach used in this systematic review is the same as that used in the initial publication, ${ }^{10}$ PROSPERO International Prospective Register of Systematic reviews (registration No: CRD42015023741). Studies included in the final synthesis from the initial publication were combined with studies identified as part of the updated search strategy.

\section{Data sources and search strategy}

The electronic databases Cochrane Library, PubMed, Embase, CINAHL, Medline and Academic Search Complete were used to undertake the search. Search parameters were adjusted to suit database requirements. A search of the databases was limited to the period between 1 January 2016 and 29 February 2020. The 1 January 2016 represents the end date of the search from the initial review. ${ }^{10}$ Keywords and MeSH terms used were: urinary catheter and/or urinary catheterisation, urinary tract infection, meatal cleaning, periurethral cleaning, antiseptic, antimicrobial, antibacterial, antibiotic and topical intervention. Further details on the search strategy are provided as supplementary material.

\section{Study inclusion and exclusion criteria}

Included studies were randomised controlled trials (RCTs) and quasi-experimental studies (pre-test and posttest design, non-RCTs) evaluating the use of antiseptic, antibacterial or non-medicated agents (such as soap and water) for cleaning the meatal, periurethral or perineal areas before indwelling catheter insertion or intermittent catheterisation or during routine meatal care. Studies were included if they involved patients requiring short-term or long-term indwelling catheters or intermittent catheterisation in hospitals, community settings, and long-term/ aged care facilities. Studies were excluded if they were not published in English language, focused solely on children ( $\leq 18$ years), included patients with pre-existing UTIs, or were published in grey literature (conference abstracts, editorial letters, reports and guidelines). Review articles, bundle interventions, studies without available data for analysis, studies that did not evaluate the control or intervention agents, and studies for which the full text was not available were also excluded.

The coprimary outcome measures were the difference in rates of CAUTI and bacteriuria in the intervention and control groups. While we accepted the definition of CAUTI and bacteriuria provided in the included studies, we also considered infection to be the outcome when clinical signs or symptoms of infection were present. ${ }^{15}$

\section{Study selection}

Database results were imported into Covidence for screening and selection. ${ }^{16}$ Screening of abstracts of articles retrieved from electronic databases for relevance to the systematic review aim was undertaken by one researcher (CC). Ten per cent of the abstracts were crosschecked by a second researcher (BM). No discrepancies were found. Full-text screening was then undertaken and assessed against the inclusion and exclusion criteria by CC. A cross check of all studies deemed to meet the inclusion criteria was also undertaken by BM. A manual search of the references lists of all included articles was undertaken to identify additional studies. Where decisions were open to disagreement, this was resolved by discussion with other members of the research team (EGH and OF).

\section{Data extraction}

The data from included studies were extracted using the Cochrane Collaboration's data collection form for RCTs and non-RCTs. Data were extracted by one researcher (CC) and then checked for accuracy by a second researcher $(\mathrm{BM})$. Extracted details included: age and sex distribution of the study population, study duration, sample size, study setting, type of intervention and duration, colony-forming unit $(\mathrm{cfu} / \mathrm{mL})$ count, bacteriuria and CAUTI rates (numerator/denominator data). For studies that reported the outcome at multiple time points, the outcome value closest to the end of the indwelling catheter in-situ period was extracted for analysis. Attempts were made to contact the authors of included studies where information was missing regarding the numerator or denominator data for calculating CAUTI rates, and when clarity was needed on the type of intervention used. One author was contacted regarding inaccuracies in reporting results and the author responded by sending the corrected version of the study manuscript.

\section{Risk-of-bias assessment}

Using Covidence and following the Cochrane Collaboration's Handbook for Systematic Reviews of Interventions (V.6., 2019), the risk of bias for studies were evaluated. ${ }^{17}$ Risk of bias was assessed as high, unclear or low. Risk of bias assessment was conducted independently by two researchers (OF and $\mathrm{CC}$ ) and disagreements resolved by discussion with a third researcher (BM). 


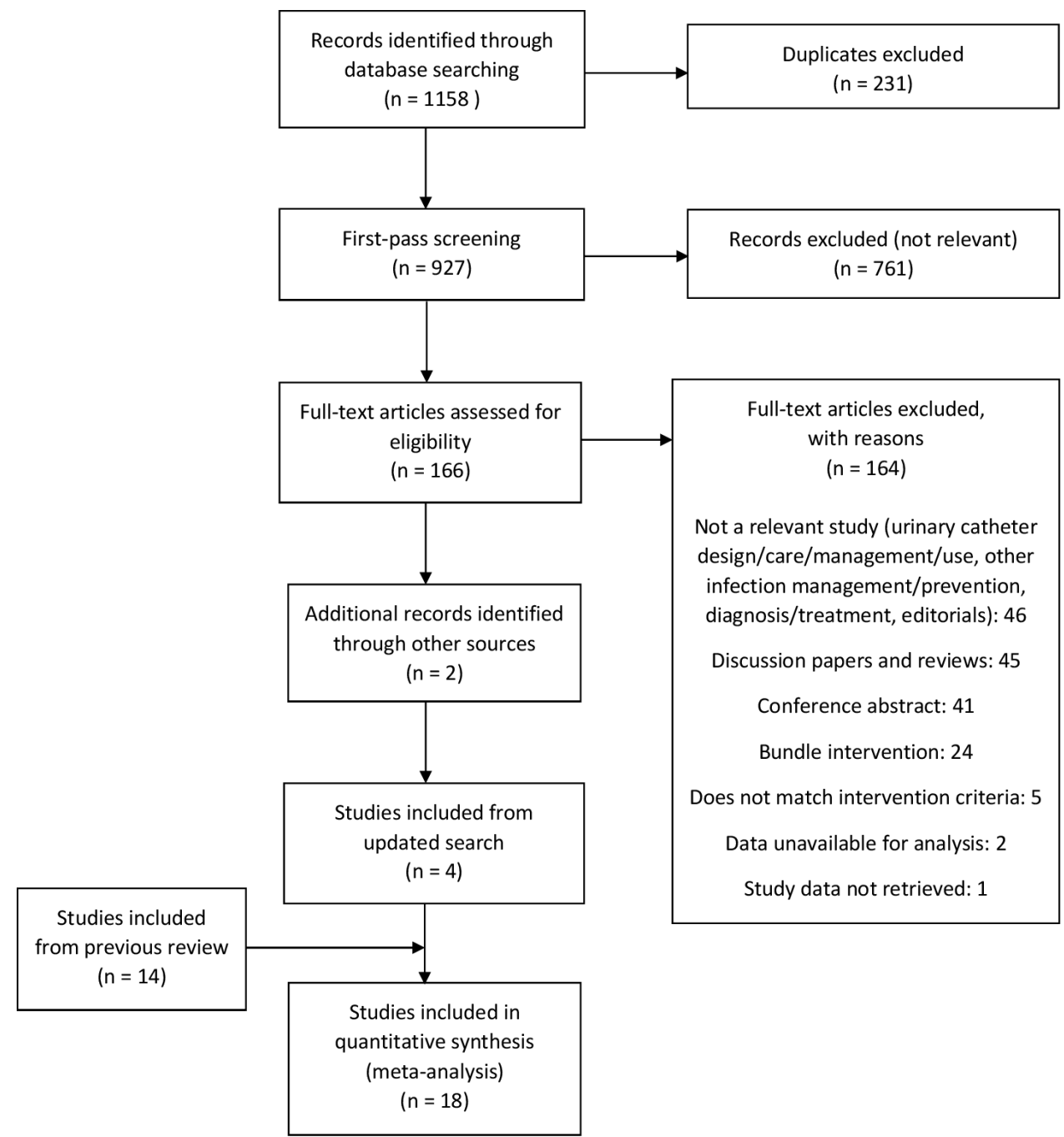

Figure 1 Preferred Reporting Items for Systematic Reviews and Meta-analyses flow diagram of study selection.

\section{Data analysis}

Data analyses were undertaken using Stata V.14 (StataCorp, College Station, Texas, USA). ORs and 95\% CIs were calculated from the proportions of patients with CAUTI and bacteriuria in the intervention and control groups. The pooled ORs were calculated and compared across intervention and control groups using the DerSimonian and Laird random effects meta-analysis model which considers possible heterogeneity between the studies during analysis. ${ }^{18}$ The likelihood of clinical heterogeneity in the included studies with regards to varying meatal cleaning agents used was considered in the a-priori data synthesis strategy. Hence, the metaanalysis was stratified by the outcome and type of meatal cleaning agent used. The $I^{2}$ statistic was used to quantify between-study heterogeneity of intervention effects. Subgroup analyses were undertaken to explore effects of aspects of study methodology (antiseptic vs non-antiseptic cleaning and administration of the intervention prior to urinary catheter insertion) on the outcome using a fixed effect model due to the low number of studies. ${ }^{19}{ }^{20}$ Assessment of reporting biases was by visual examination of the funnel plot. A 0.05 level of significance was used without adjustment for multiplicity (number of comparisons of meatal cleaning agents). Effect sizes and their precision, in addition to significance were considered when interpreting the results.

\section{Patient and public involvement}

No patient involved.

\section{RESULTS}

In total, 927 articles were retrieved from electronic database searches and their abstracts were screened for relevance to the systematic review aim. After evaluating these articles against the inclusion and exclusion criteria, four studies were identified for inclusion. These four studies were added to the 14 studies included in the previous review $^{10}$; hence, a total 18 studies were included in this systematic review and meta-analysis (figure 1 ).

The characteristics of the included studies are presented in table 1 . The majority of studies were RCTs $(n=15)$. There was considerable diversity in the types of interventions (meatal cleaning agent) used and whether the intervention was applied to the meatal area 


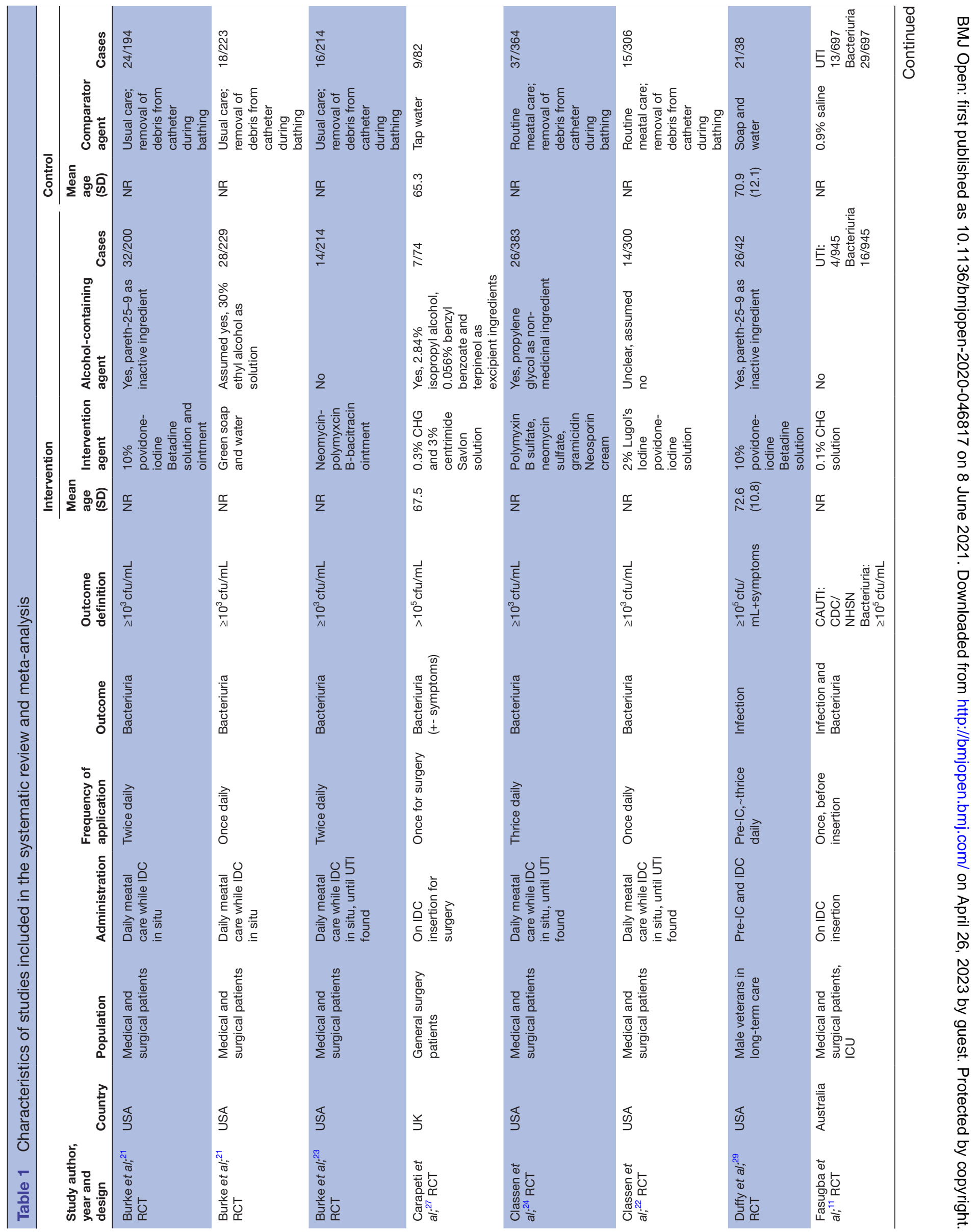




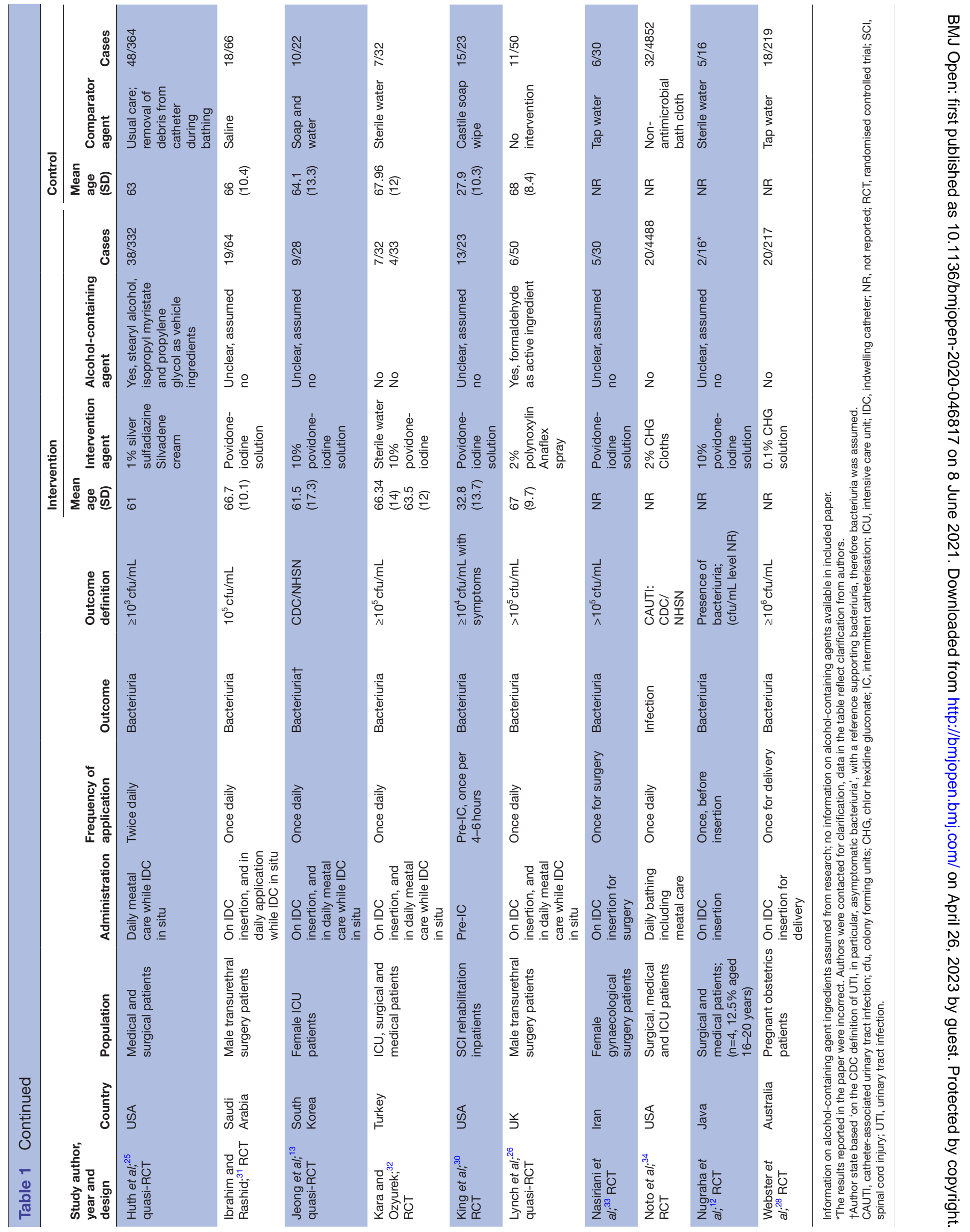


during ongoing meatal care, prior to catheter insertion only or a combination of both. Of the 18 studies, two compared povidone-iodine with routine (or standard) meatal care, which involved removal of debris from the catheter during bathing; ${ }^{21} 22$ one compared green soap with routine meatal care ${ }^{21}$ four compared an antibacterial agent (neomycin-polymyxcin B, $1 \%$ silver sulfadiazine silvadene, $2 \%$ polynoxylin) with routine meatal care ${ }^{23-26}$ two compared chlorhexidine $(0.1 \%$ and $0.3 \%$ plus and $3 \%$ centrimide) with tap water; ${ }^{27} 28$ three compared povidone-iodine with soap and water, ${ }^{13} 2930$ one compared chlorhexidine $(0.1 \%)$ with saline; ${ }^{11}$ one compared povidone-iodine with saline $;{ }^{31}$ two compared povidone-iodine with sterile water; ${ }^{12} 32$ one compared povidone-iodine with tap water; ${ }^{33}$ and one compared antimicrobial cloth with chlorhexidine $(2 \%)$ compared with a non-antimicrobial cloth. ${ }^{34}$

The term 'infection' was often referred to as the primary outcome in studies. However, the definition of infection varied and for most studies, this term was used when bacteria were present in the urine with or without clinical symptoms. We recoded outcomes to be either bacteriuria or infection-where the definition of infection must have included signs/symptoms of a UTI. Two studies reported CAUTI as the only outcome, 15 studies reported bacteriuria as the only outcome and one study reported both CAUTI and bacteriuria as outcomes.

\section{Effect of meatal cleaning on the incidence of bacteriuria and CAUTI}

A forest plot displaying the results of random-effect meta-analyses for the effect of meatal cleaning on the incidence of both bacteriuria and CAUTI combined, stratified by meatal cleaning agent is presented in figure 2. For the study that reported both CAUTI and bacteriuria as outcomes, ${ }^{11}$ only data for bacteriuria were included because bacteriuria was the outcome in majority of studies. There was no evidence of differences in the incidence of bacteriuria or CAUTI between the intervention and control groups when comparing the different agents: povidone-iodine versus routine care (OR 1.19, $95 \%$ CI 0.75 to $1.87 ; \mathrm{p}=0.46$ ); green soap and water versus routine care (OR 1.59, 95\% CI 0.85 to 2.96; $\mathrm{p}=0.15$ ), chlorhexidine versus tap water (OR 1.04, 95\% CI 0.59 to 1.83 ; $\mathrm{p}=0.89$ ); povidone-iodine versus soap and water (OR $0.88,95 \%$ CI 0.48 to $1.62 ; \mathrm{p}=0.69$ ); povidone-iodine versus saline (OR $1.13,95 \% \mathrm{CI} 0.53$ to $2.41 ; \mathrm{p}=0.76$ ); povidone-iodine versus sterile water (OR $0.42,95 \%$ CI 0.14 to $1.24 ; \mathrm{p}=0.12$ ); povidone-iodine versus tap water (OR $0.80,95 \%$ CI 0.22 to $2.97 ; \mathrm{p}=0.74$ ) and chlorhexidine versus antimicrobial cloths (OR $0.67,95 \%$ CI 0.39 to 1.18 ; $\mathrm{p}=0.17$ ).

There was potential evidence of a small difference in the incidence of bacteriuria or CAUTI between the intervention and control groups overall (pooled OR $0.84,95 \% \mathrm{CI}$ 0.69 to $1.02 ; \mathrm{p}=0.071$ ), with the $\mathrm{CI}$ nearly excluding 1 . This also applies to the comparison of antibacterial agent vs routine care (OR $0.75,95 \%$ CI 0.55 to $1.01 ; \mathrm{p}=0.055)$.
The comparison of chlorhexidine versus saline demonstrated statistical evidence of differences between the intervention and control group (OR $0.40,95 \%$ CI 0.21 to $0.74 ; p=0.003)$. Overall results showed evidence of heterogeneity $\left(I^{2}=13.2 \%\right.$; $\left.p=0.296\right)$ among the included studies.

Separate forest plots showing the effect of meatal cleaning on the incidence of bacteriuria and CAUTI are presented as online supplemental material 1 (online supplemental figures 1, 2 and table 1, respectively). Sixteen studies were included in the meta-analysis evaluating the effect of meatal cleaning on the incidence of bacteriuria only while three studies were included in the meta-analysis evaluating the effect of meatal cleaning on the incidence of CAUTI only. ${ }^{1129} 34$ Analyses showed no statistically significant difference in the incidence of bacteriuria (pooled OR $0.84,95 \%$ CI 0.70 to 1.01 ; $\mathrm{p}=0.06$ ), noting this was close to being statistically significant. In addition, 12 of the 16 studies in this meta-analysis had findings in the same direction, a benefit to antiseptics (online supplemental figure 1). In contrast, there was a statistically significant difference in the effect of meatal cleaning using an antiseptic (chlorhexidine or povidineiodine) versus a comparator agents (saline, soap or antimicrobial cloths) on the incidence of CAUTI (pooled OR $0.65,95 \%$ CI 0.42 to $0.99 ; \mathrm{p}=0.047$, online supplemental figure 2).

Effect of antiseptic versus non-antiseptic meatal cleaning prior to urinary catheterisation on the incidence of bacteriuria Six studies explored the effect of using an antiseptic meatal cleaning agent prior to catheter insertion, compared with a non-antiseptic agent, on the incidence of bacteriuria (figure 3)..$^{11} 1227283033$ There was evidence of a potential difference in the incidence of bacteriuria when comparing the use of antiseptic and non-antiseptic agents (pooled $\mathrm{OR}=0.67,95 \%$ CI 0.44 to 1.03 ; $\mathrm{p}=0.065$; figure 3$)$.

Effect of antiseptic versus non-antiseptic meatal cleaning prior to urinary catheterisation on the incidence of CAUTI

Two studies explored the effect of using an antiseptic meatal cleaning agent prior to catheter insertion, compared with a non-antiseptic agent, on the incidence of CAUTI. ${ }^{11}{ }^{29}$ One used $10 \%$ povidone-iodine and found no difference, ${ }^{29}$ while the other study used chlorhexidine $(0.1 \%)$ and identified a significant reduction in CAUTI ${ }^{11}$ (online supplemental figure 3).

\section{Risk of bias}

Results showed that the level of risk of bias varied between the included studies (figure 4). The majority of studies $(n=15)$ were assessed to have a high or unclear risk of bias for reporting of blinding processes used in the studies. The vast majority of studies were biased in the categories of allocation and performance. The studies conducted by Noto $e t a l^{34}$ and Fasugba $e t a l^{11}$ were deemed to be at lowest risk of bias. 


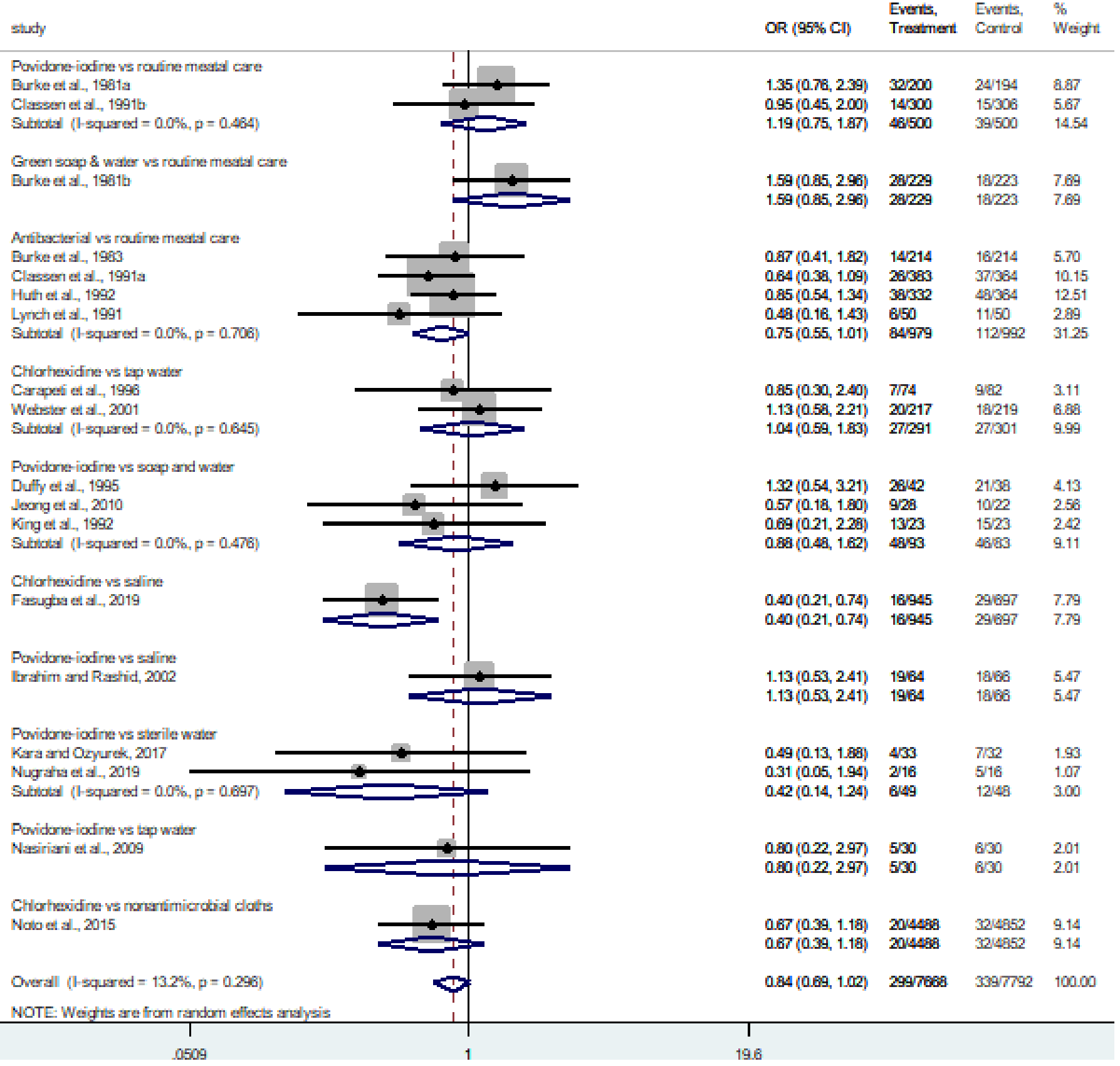

Figure 2 Forest plot displaying random-effect meta-analysis of the effect of meatal cleaning on the incidence of bacteriuria and or catheter-associated urinary tract infections (CAUTIs; results stratified by meatal cleaning agent). Duffy et al., 1995 and Noto et al., 2015 all report CAUTI as the outcome, while Fasugba et al., 2019 report both CAUTI and bacteriuria. Bacteriuria data only from Fasugba et al, 2019 is included in this analysis.

\section{Publication bias}

Visual inspection of the funnel plot showed no evidence of publication bias (figure 5).

\section{DISCUSSION}

Findings from this systematic review suggest that broadly speaking, using antiseptics for meatal cleaning may reduce the risk of bacteriuria or CAUTI in some instances, but uncertainty remains for antiseptics as a broad group. The uncertainly is in part driven by the diversity of antiseptics reviewed and variations in outcomes and populations.
Although the ORs are not statistically significant at a level of $0.05,{ }^{35}$ the results are clinically meaningful for some specific subsets of antiseptics and or outcomes. For this reason, we discuss some important subsets below, including limitations. The evidence appears to be stronger and more consistent, for example, prior to urinary catheterisation. There also appears to be emerging evidence that using chlorhexidine prior to urinary catheterisation may provide benefit in reducing CAUTI. Preventing CAUTI is important for a number of reasons. Prevention of CAUTI is vital, not only because of associated morbidity, mortality 


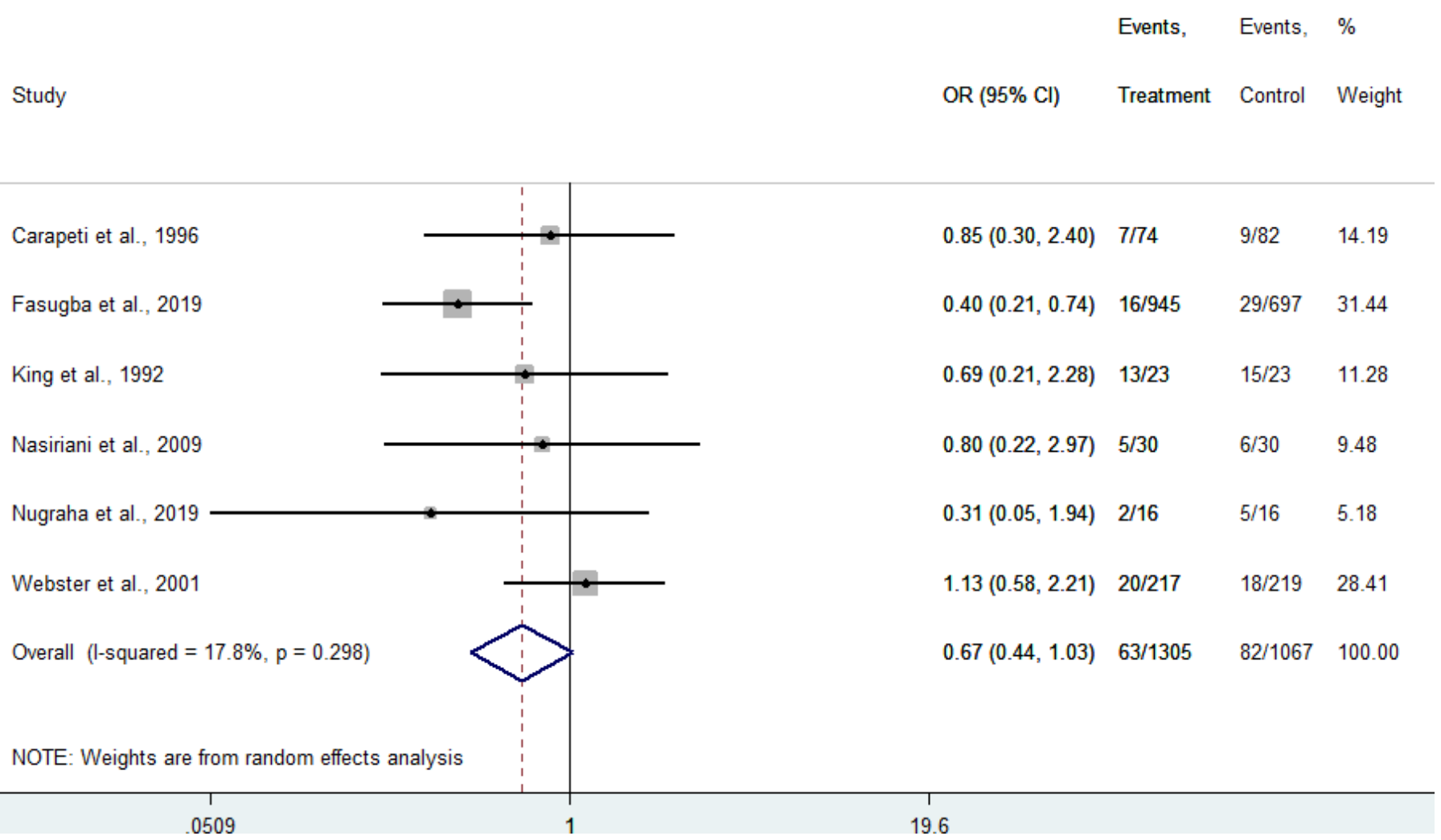

Figure 3 Random-effect meta-analysis of the effect of using an antiseptic meatal cleaning agent (povidone-iodine, chlorhexidine) versus a non-antiseptic agent (soap and water, tap water, sterile water or saline) prior to catheter insertion on the incidence of bacteriuria.

and increased length of stay in hospital, ${ }^{2-5}$ but because of the added threats posed by increasing antimicrobial resistance. $^{36}$

\section{The effect of meatal cleaning in reducing the risk of bacteriuria}

The meta-analysis exploring the effect of meatal cleaning in reducing the risk of bacteriuria, included studies that used antiseptics for routine meatal cleaning, for example, post catheter insertion, as well as studies using antiseptics as part of the catheter insertion process (prior to urinary catheterisation; figure 2). The antiseptics used in studies included in this meta-analysis also varied (table 1). When all studies were combined, the results indicated a potential benefit of using antiseptics, in reducing the risk bacteriuria or CAUTI (pooled OR $0.84,95 \%$ CI 0.70 to 1.01 ). It is also worth noting that 13 of the 18 studies in figure 2 had point estimates less than one that is, direction favouring antiseptics. Although not statistically significant at an arbitrary level of 0.05 , these results have clinical implications, noting it is difficult to interpret given the heterogeneity of antiseptics and timing of their use. In subanalysis, some benefit of using an antibacterial agent versus routine (standard) care was identified (OR $0.75,95 \%$ CI 0.55 to 1.01). Bacteriuria as a clinical outcome is arguably of little clinical relevance. However, studies to date have largely used this as the primary outcome. We discussion the results related to CAUTI later in this discussion. One argument in favour of bacteriuria as an outcome, is that reducing this may reduce antimicrobial use. Research has indicated the frequency of inappropriate treatment for bacteriuria. In supplementary material, results using a random effect model are also presented (online supplemental figures 3-6).

The use of antiseptics prior to urinary catheterisation

In studies specifically exploring the use of antiseptics prior to urinary catheterisation, a meta-analysis indicated some value of antiseptics in preventing bacteriuria, compared with non-antiseptic agents (pooled $\mathrm{OR}=0.67$, $95 \%$ CI 0.44 to $1.03 ; p=0.065$ ). Five of the six studies included in the meta-analysis had findings in the same direction, a benefit to antiseptics (figure 3). The metaanalysis was largely influenced by two studies, indicating differing results, but both using chlorhexidine $0.1 \%$. One of these two studies, a multicentre study involving three hospitals and included all patients in each hospital, indicated a statistically significant benefit when using antiseptics (chlorhexidine $0.1 \%) .{ }^{11}$ The second study, a single-centre study in an obstetric population, indicated no benefit, with a non-statistically significant result.$^{28}$ For consistency, in the meta-analysis, the outcomes presented were bacteriuria. 


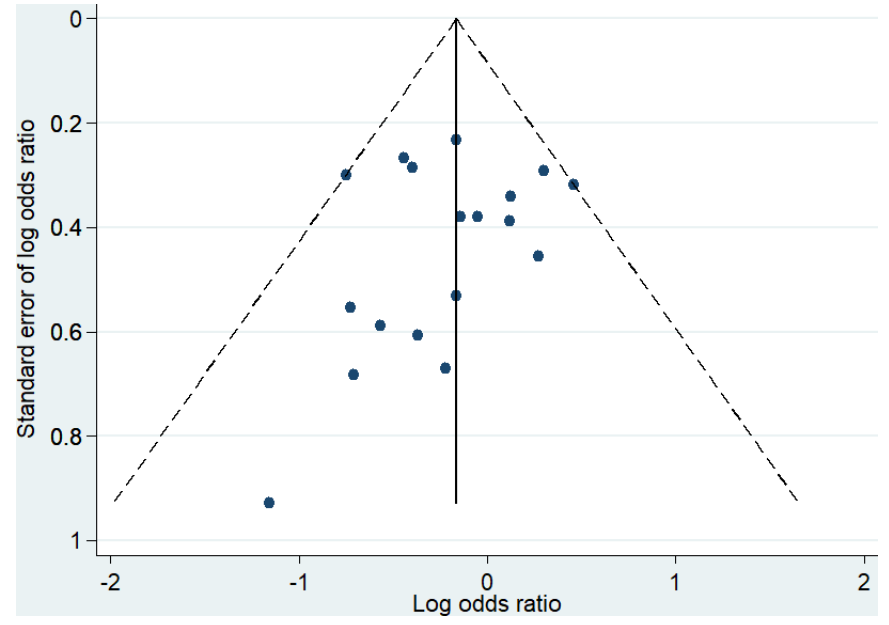

Figure 5 Funnel plot of the included studies.

\section{The use of antiseptics prior to urinary catheterisation and effect on CAUTI}

Arguably the most important clinical outcome is CAUTI. We identified two studies evaluating the use of antiseptics prior to catheterisation, with CAUTI as the primary outcome. ${ }^{1129}$ These two studies used different antiseptics. Fasugba et al found a significant reduction in CAUTI, associated with the use of chlorhexidine $0.1 \%$ (IRR $0.06,95 \%$ CI 0.01 to $0.32,<\mathrm{p}=0.001) .{ }^{11}$ In a follow-up cost-effectiveness evaluation, the authors found that using chlorhexidine $0.1 \%$ was cost saving. ${ }^{37}$ Duffy et $a l^{29}$ evaluated the use of povidone-iodine prior to catheterisation, in participants who had indwelling catheters or were undertaking intermittent catheterisation. Duffy and colleagues did not identify a benefit from using povidone iodine. ${ }^{29}$ It is worth noting other important differences. The control phase included a clean catheterisation technique, that is, not requiring a sterile field. The intervention phase, which used povidone-iodine, also included the use of a sterile procedure. The average follow-up period for participants was 63 days. As time from catheter insertion increases, the likelihood of an infection being related to insertion practices diminishes.

In contrast, participants in the study undertaken by Fasugba $e t a l^{11}$ were followed up for 7 days only. Further, unlike the study by Duffy and colleagues, there were no other major changes that could potentially confound the outcome-such as a change in the procedure. The risk-ofbias assessment also suggests less bias in the study undertake by Fasugba.

There were no report adverse events using low-dose chlorhexidine prior to catheterisation. ${ }^{11}$ Chlorhexidine prior to catheterisation is anticipated to have high acceptability noting it is already used in many clinical settings. Like most antiseptics, feasibility is unlikely to be an issue, given the relative ease of implementation, only requiring a simple product substitution. The cost-effectiveness (and cost saving) for the use of chlorhexidine $0.1 \%$ has been demonstrated and accounted for uncertainty, thus reducing equity issues. ${ }^{37}$

Figure 4 Risk-of-bias assessment. 


\section{Limitations}

A limitation of this review is that data extraction was undertaken by one person, noting that a second reviewer checked data extraction for accuracy. There was considerable heterogeneity in intervention and population groups, in particular those presented in figure 2. We acknowledge that two of the authors of this systematic review led one of the included studies. ${ }^{11}$ To ensure there was balance, we included three authors on this paper that had no involvement in this study.

\section{CONCLUSION}

This paper represents the latest evidence on the role of using antiseptics in people with urinary catheters, for the purpose of infection prevention. In turn, we hope this will inform local policy and practice, as well as infection control guidelines more generally. The results from this review suggest that antiseptics may be of value for meatal cleaning on the incidence of CAUTI, compared with non-antiseptic agents. In other areas of infection prevention and control, rather than a 'broad brush' approach to determining the effect of antiseptics on a specific outcome, often individual agents are examined. For example, in the case of prevention of surgical site infection, comparisons have been made for chlorhexidine versus iodophor or alcoholic versus non-alcoholic based antiseptics. ${ }^{38} 39$ The evidence to support the role of antiseptics as a broad group in reducing bacteriuria and CAUTI is challenged by variations in the diversity of antiseptics and the utility of bacteriuria as an outcome. Based on the evidence identified in this review and after careful consideration of the outcomes and methods used in included studies, we believe that there is emerging but limited evidence of the role of chlorhexidine $0.1 \%$ prior to urinary catheterisation, in reducing CAUTI. However, we acknowledge this evidence is limited to one multicentred study. Given the low number of included studies using CAUTI as the primary outcome, additional studies in this area are required, ensuring that important confounders are controlled for in the study design.

\section{Author affiliations}

${ }^{1}$ School of Nursing and Midwifery, The University of Newcastle-Central Coast Campus, Ourimbah, New South Wales, Australia

${ }^{2}$ School of Medicine and Public Health, The University of Newcastle, Callaghan, New South Wales, Australia

${ }^{3}$ School of Nursing, Midwifery and Social Work, University of Queensland, Brisbane, Queensland, Australia

${ }^{4}$ Alliance for Vascular Access Teaching and Research (AVATAR), Menzies Health Institute Queensland, Griffith University, Nathan, Queensland, Australia

${ }^{5}$ Herston Infectious Disease Institute, Metro North Hospitals and Health Service, Brisbane, Queensland, Australia

${ }^{6}$ Nursing Research Institute, St Vincent's Health Network Sydney, St Vincent's Hospital Melbourne \& Australian Catholic University, Sydney, New South Wales, Australia

\section{Twitter Brett Mitchell @1healthau and Claire M Rickard @claire_avatar}

Contributors OF and BM designed the study. OF conducted the search. CC conducted the primary review of the articles and data extraction. $\mathrm{CC}, \mathrm{OF}$ and $\mathrm{BM}$ conducted the risk-of-bias assessment. OF, BM and EH conducted the analysis. All authors provided input into the interpretation of the data, writing the paper, provided critical review and approved the final version of the paper.

Funding The authors have not declared a specific grant for this research from any funding agency in the public, commercial or not-for-profit sectors.

Competing interests BM reports personal fees from MSD, grants from Cardinal Health, grants from Senver, outside the submitted work.

Patient consent for publication Not required.

Ethics approval As this is a systematic review, ethics approval was not required.

Provenance and peer review Not commissioned; externally peer reviewed.

Data availability statement Data are available upon reasonable request. Please contact authors as required.

Supplemental material This content has been supplied by the author(s). It has not been vetted by BMJ Publishing Group Limited (BMJ) and may not have been peer-reviewed. Any opinions or recommendations discussed are solely those of the author(s) and are not endorsed by BMJ. BMJ disclaims all liability and responsibility arising from any reliance placed on the content. Where the content includes any translated material, BMJ does not warrant the accuracy and reliability of the translations (including but not limited to local regulations, clinical guidelines, terminology, drug names and drug dosages), and is not responsible for any error and/or omissions arising from translation and adaptation or otherwise.

Open access This is an open access article distributed in accordance with the Creative Commons Attribution Non Commercial (CC BY-NC 4.0) license, which permits others to distribute, remix, adapt, build upon this work non-commercially, and license their derivative works on different terms, provided the original work is properly cited, appropriate credit is given, any changes made indicated, and the use is non-commercial. See: http://creativecommons.org/licenses/by-nc/4.0/.

ORCID iDs

Brett Mitchell http://orcid.org/0000-0003-4220-8291

Elizabeth Holliday http://orcid.org/0000-0002-4066-6224

Claire M Rickard http://orcid.org/0000-0002-6341-7415

\section{REFERENCES}

1 Hooton TM, Bradley SF, Cardenas DD, et al. Diagnosis, prevention, and treatment of catheter-associated urinary tract infection in adults: 2009 international clinical practice guidelines from the infectious diseases Society of America. Clin Infect Dis 2010;50:625-63.

2 Lo E, Nicolle LE, Coffin SE, et al. Strategies to prevent catheterassociated urinary tract infections in acute care hospitals: 2014 update. Infect Control Hosp Epidemiol 2014;35 Suppl 2:S32-47.

3 Smith DRM, Pouwels KB, Hopkins S, et al. Epidemiology and health-economic burden of urinary-catheter-associated infection in English NHS hospitals: a probabilistic modelling study. J Hosp Infect 2019;103:44-54.

4 Daniels KR, Lee GC, Frei CR. Trends in catheter-associated urinary tract infections among a national cohort of hospitalized adults, 20012010. Am J Infect Control 2014;42:17-22.

5 Mitchell BG, Ferguson JK, Anderson M, et al. Length of stay and mortality associated with healthcare-associated urinary tract infections: a multi-state model. J Hosp Infect 2016;93:92-9.

6 Smith DRM, Pouwels KB, Hopkins S, et al. Epidemiology and health-economic burden of urinary-catheter-associated infection in English NHS hospitals: a probabilistic modelling study. J Hosp Infect 2019;103:44-54.

7 Meddings J, Rogers MAM, Krein SL, et al. Reducing unnecessary urinary catheter use and other strategies to prevent catheterassociated urinary tract infection: an integrative review. BMJ Qual Saf 2014;23:277-89.

8 Meddings J, Saint S, Krein SL, et al. Systematic review of interventions to reduce urinary tract infection in nursing home residents. J Hosp Med 2017;12:356-68.

9 Mitchell BG, Northcote M, Cheng AC, et al. Reducing urinary catheter use using an electronic reminder system in hospitalized patients: a randomized stepped-wedge trial. Infect Control Hosp Epidemiol 2019;40:427-31.

10 Fasugba O, Koerner J, Mitchell BG, et al. Systematic review and meta-analysis of the effectiveness of antiseptic agents for meatal cleaning in the prevention of catheter-associated urinary tract infections. J Hosp Infect 2017;95:233-42.

11 Fasugba O, Cheng AC, Gregory V, et al. Chlorhexidine for meatal cleaning in reducing catheter-associated urinary tract infections: a 
multicentre stepped-wedge randomised controlled trial. Lancet Infect Dis 2019;19:611-9.

12 Nugraha A, Puspita T, Patimah IIN. Comparison of $10 \%$ povidone iodine and sterile water as a periuretra cleansing solutionbefore the insertion of indwelling urinecathetheron the occurance of bacteria. International Journal of Pharmaceutical Research 2019;11:810-6.

13 Jeong I, Park S, Jeong JS, et al. Comparison of catheter-associated urinary tract infection rates by perineal care agents in intensive care units. Asian Nurs Res 2010;4:142-50.

14 Moher D, Liberati A, Tetzlaff J, et al. Preferred reporting items for systematic reviews and meta-analyses: the PRISMA statement. Int $J$ Surg 2010;8:336-41.

15 Centers for Disease Control and Prevention. CDC/NHSN surveillance definitions for specific types of infections 2020., 2020. Available: https://www.cdc.gov/nhsn/PDFs/pscManual/17pscNosInfDef current.pdf

16 Veritas Health Innovation. Covidence systematic review software. Melbourne 2020 https://www.covidence.org/

17 Higgins JP, Savović J, Page MJ. Assessing risk of bias in a randomized trial. Cochrane Handbook for Systematic Reviews of Interventions 2019:205-28.

18 DerSimonian R, Laird N. Meta-Analysis in clinical trials. Control Clin Trials 1986:7:177-88.

19 Tufanaru C, Munn Z, Stephenson M, et al. Fixed or random effects meta-analysis? common methodological issues in systematic reviews of effectiveness. Int J Evid Based Healthc 2015;13:196-207.

20 Mathes T, Kuss O. A comparison of methods for meta-analysis of a small number of studies with binary outcomes. Res Synth Methods 2018:9:366-81.

21 Burke JP, Garibaldi RA, Britt MR, et al. Prevention of catheterassociated urinary tract infections. efficacy of daily meatal care regimens. Am J Med 1981;70:655-8.

22 Classen DC, Larsen RA, Burke JP, et al. Prevention of catheterassociated bacteriuria: clinical trial of methods to block three known pathways of infection. Am J Infect Control 1991b;19:136-42.

23 Burke JP, Jacobson JA, Garibaldi RA, et al. Evaluation of daily meatal care with poly-antibiotic ointment in prevention of urinary catheterassociated bacteriuria. J Urol 1983;129:331-4.

24 Classen DC, Larsen RA, Burke JP, et al. Daily meatal care for prevention of catheter-associated bacteriuria: results using frequent applications of polyantibiotic cream. Infect Control Hosp Epidemiol 1991:12:157-62.

25 Huth TS, Burke JP, Larsen RA, et al. Randomized trial of meatal care with silver sulfadiazine cream for the prevention of catheterassociated bacteriuria. J Infect Dis 1992;165:14-18.
26 Lynch MJ, MacDermott JP, Byrne DJ, et al. Use of an antibacterial powder spray to prevent post prostatectomy urinary infection. $J R$ Soc Med 1991;84:667.

27 Carapeti EA, Andrews SM, Bentley PG. Randomised study of sterile versus non-sterile urethral catheterisation. Ann R Coll Surg Engl 1996;78:59.

28 Webster J, Hood RH, Burridge CA, et al. Water or antiseptic for periurethral cleaning before urinary catheterization: a randomized controlled trial. Am J Infect Control 2001;29:389-94.

29 Duffy LM, Cleary J, Ahern S, et al. Clean intermittent catheterization: safe, cost-effective bladder management for male residents of $\mathrm{Va}$ nursing homes. J Am Geriatr Soc 1995;43:865-70.

30 King RB, Carlson CE, Mervine J, et al. Clean and sterile intermittent catheterization methods in hospitalized patients with spinal cord injury. Arch Phys Med Rehabil 1992;73:798-802.

31 Ibrahim AIA, Rashid M. Comparison of local povidone-iodine antisepsis with parenteral antibacterial prophylaxis for prevention of infective complications of TURP: a prospective randomized controlled study. Eur Urol 2002;41:250-6.

32 Kara A, Özyürek P. The effect of periuretral care and follow-up on bacteriuria in patients with urinary catheter: a comparison of three solutions. Journal of Clinical and Experimental Investigations 2017:8:54-60.

33 Nasiriani K. Comparison of the effect of WA TER vs povidoneiodine solution for $\mathrm{P}$ eriu rethral cleaning in wo men requiring an indwelling catheter prior to gynecologic Surg E ry. Urologic Nursing 2009;29:119.

34 Noto MJ, Domenico HJ, Byrne DW, et al. Chlorhexidine bathing and health care-associated infections: a randomized clinical trial. JAMA 2015;313:369-78.

35 Kyriacou DN. The enduring evolution of the $\mathrm{P}$ value. JAMA 2016;315:1113-5.

36 Paul R. State of the globe: rising antimicrobial resistance of pathogens in urinary tract infection. J Glob Infect Dis 2018;10:117-8.

37 Mitchell BG, Fasugba O, Cheng AC, et al. Chlorhexidine versus saline in reducing the risk of catheter associated urinary tract infection: a cost-effectiveness analysis. Int J Nurs Stud 2019;97:1-6.

38 Peel TN, Watson E, Lee SJ. Randomised controlled trials of alcoholbased surgical site skin preparation for the prevention of surgical site infections: systematic review and meta-analysis. $J$ Clin Med 2021;10. doi:10.3390/jcm10040663. [Epub ahead of print: 0902 2021].

39 Dumville JC, McFarlane E, Edwards P, et al. Preoperative skin antiseptics for preventing surgical wound infections after clean surgery. Cochrane Database Syst Rev 2015;4:CD003949. 